\title{
A SEMANA DA ARTE MODERNA E A CRISE DOS ANOS 20
}

\author{
Ana Lucia T. V. Ramos da Silva \\ Elisabeth Rochadel
}

A Semana de Arte Moderna de 1922 inaugura uma nova fase para as artes e letras no Brasil, e uma análise mais profunda de suas ligações com a politica da República Velha poderá levar a conclusões diversas daquelas apresen tadas pela historiografia tradicional. Nascida em São Paulo, ela inspirou posições radicais bem de acordo com as tendências da época, uma vez que encontramos no Brasil, no ano de 1922, a eclosão do movimento tenentista, os gérmes da cisão oligárquica paulista que culminam com a formação do partido Democrático, a oposição gaúcha enfrentando a "ditadura" de Borges de $\mathrm{Me}$ deiros, passo inicial para o sangrento 1923, e mais tarde a Aliança Liberal e o próprio movimento revolucionário de 1930.

Enfatiza-se que apesar dos radicalismos, a única ligação da Semana de Arte de 1922 com a política virá via modernismo ou nacionalismo, ou seja, pelo que a mesma despertou e não pelo engajamento dos que a compuseram.

Para estudar o movimento modernista optou-se por detectar manifestações nacionalistas anteriores a 1922 e nelas procurar os gérmes dos nascentes nacionalismos e modernismos brasileiros. Não se pretende utilizar nacionalismo e modernismo como sinônimos, já que entendemos o primeiro como uma via pra chegar-se ao segundo. Portanto, falar-se-á em nacionalismo e, posteriormente, em modernismo enquanto movimento cultural.

A partir de 1800 , o nacionalismo foi, incontestavelmente, uma das mais poderosas forças que moldaram a história do mundo ocidental, pois na forma romântica emergiu principalmente contra a divisão territorial da Europa Ocidental, realizada através do Congresso de Viena, que não soubera respeitar as nacionalidades.

Após 1848 cresceu o movimento em prol da grandeza nacional e do direito de cada povo que, unido por laços culturais e étnicos, deveria decidir seus próprios destinos. O Nacionalismo, sustituindo a liberdade individual pelo poder nacional e pela independência coletiva, provocou uma mudança no liberalismos democrático ao gerar a democracia de massas. Nesta, o povo abdica de sua liberdade e passa a ser manipulado pelos partidos e pelo poder executivo. O nacionalismo, assim, conseguiu questionar o liberalismo. Juntamente com o processo de industrialização, foram colocados os objetivos nacionais acima dos objetivos individuais. Era o nacionalismo chauvinista, reponsável pela unificação da Alemanha e da Itália da década de 70 do século XIX, e pela formação dọ Pan-Eslavismo e o Pan-Germánismo, como também pela conflagração da 
Primeira Guerra Mundial.

No Brasil, Manuel Bandeira, em suas "Crônicas da Província do Brasil», expressa com precisão a atmosfera resultante da Primeira Grande Guerra:

«A Guerra de 1914 provocou em todo o mundo uma revivescência do sentimento nacionalista ativo. As elites sonhavam com uma organizaçăo politica e social mais justa numa humanidade sem fronteiras. Mal, porém, se declarou o conflito o espirito feroz da pátria apoderou-se de todos, inclusive dos socialistas. Nas nações beligerantes o movimento nacionalista assumiu naturalmente as formas do patriotismo mais agressivo. Em paises mais remotamente interessados, como foi o caso do nosso, o sentimento nativista exprimiu-se nas artes por uma volta aos assuntos nacionais" (1)

Em 1915, no pensamento de Wilson Martins, começava um período de intensa reafirmação nacionalista, na qual se reconciliavam velhos e moços, revolucionários e conservadores, militares e civis. Havia no ar o sentimento obscuro de que o mundo se acabava, de que alguma coisa de desconhecido estava para acontecer, mas o veículo comum de todas as reformas possiveis ou imagináveis era o nacionalismo (2).

Em 1916, a revista "Resenha do Mês" inseria uma nota intitulada "Nacionalização da Arte", onde o autor (A.R.), afirmava que "a idéia de nacionalismo anda agora em todos os espíritos" e que a revista é fruto desta mesma idéia (3).

Acreditava-se que o nacionalismo brasileiro superara o individualismo nacionalista romântico, numa afirmação contida nesta mesma resenha: "Nós não somos um povo inferior, nem decadente. Apenas não atingimos ainda a maturidade de nação, no sentido científico do vocábulo, isto é, de agremiação política e social, tendo um pensamento, um sentir, uma ação, que sejam verdadeiramente a sintese da energia coletivan (4).

O nacionalismo aí preconizado é aplicável às manifestações artísticas, e segundo o mesmo autor, “Não devemos consentir que a arte brasileira recém saída à coesão do sentimento autônomo, se sirva de formas peregrinas, quando lhe devemos imprimir o sinete propriamente nacional" (5).

Ainda no ano de 1916, na Revista do Brasil do mês de outubro, encontra-se o seguinte comentário: «Não há duas opiniões sobre a campanha nacionalista que se faz, neste momento em quase todo o Brasil. É geral a convicção, ou pelo menos, o sentimento de que ela responde a uma necessidade incoercível». $\mathrm{E}$ em dezembro, este mesmo periódico declara que «um dos mais belos resultados da campanha nacionalista de Olavo Bilac é a fundação da Liga Nacionalista", e suas excursões pelo sul do país, realizando o "seu apostolado de civismo e patriotismon (6).

Engajados neste movimento, os estudantes das escolas superiores do Distrito Federal fundaram uma sociedade de propaganda nacionalista, "Colméia", que promovia conferências sobre o Brasil, realizadas por Olavo Bilac, Medeiros de Albuquerque e Roquete Pinto, onde este último, conhecido por ser um mestre em nacionalismo, afirmava que «nos paises da América do Sul, a desnacionalização era um problema sério" (7). 
Outro fato relevante neste ano foi a promulgação do Código Civil que foi chamado pela Revista do Brasil como o fato culminante do mês de outubro e atestado da «nossa maturidade enquanto povo e nação" (8).

O movimento nacionalista, a fundação da Revista do Brasil, a promulgação do Código Civil, anunciava uma sensivel mundaça no quadro de valores; começava, então, na história de nossa inteligência, a era modernista.

\section{Segundo Sílvio Castro,}

«1917 é um ano importante para o movimento da opiniåo pública brasileira. A continuidade da guerra em plena operaçăo provocando tragédias que năo interessavam tăo somente à Europa, mas todo o mundo; a revoluçăo soviética, instaurando um novo regime que propunha uma nova dialética com ressonâncias internacionais; $\mathrm{a}$ dramática atmosfera por que viyem entåo todas as naçoes e povos finalmente integrados numa ilimitada e inquieta comunidade universal, sâo fatores de modificaç̋es no homem brasileiro, principalmente paulista. São fatores que interessavam profundamente à vida nacional, dando-lhe novos endereços tanto no setor econômico-social, como cultural» (9).

Especificamente no plano cultural, é o momento marcado pela contestação dadaista de que Oswald de Andrade será o máximo expoente no Brasil e pela exposição expressionista de Anita Malfatti, promovida pelos jovens escritores paulistas.

A idéia nacionalista parecia nortear o ideário coletivo, sendo no entanto necessário ressaltar que nesse momento muitos futuros modernistas mostravamse indiferentes ao programa nacionalista e ao programa de vanguarda. Exemplos disso são os livros publicados nesse ano de Mário de Andrade, Manuel Bandeira, Guilherme de Almeida e Menotti del Picchia.

O nacionalismo corrente, identificado com a tradição, podia ser uma defesa eficaz contra o cosmopolitismo futurista, estruturalmente correspondente ao Esperanto, no plano lingüístico, e, no plano político à «desnacionalizaçãon, isto é, ao socialismo, que pregava então, com ingenuidade «o fim das pátrias". Tudo isso adquire a indispensável uterceira dimensão" se pensarmos que 1917 é o ano da Revolução Russa e da grande greve operária de São Paulon (10).

A exposição de Anita Malfatti realizada em dezembro de 1917 na rua Líbero Badaró, pelo clima de escândalo gerado em torno dela e pelo artigo «Paranóia e Mistificação" de Monteiro Lobato, que saiu no "Estadinho", órgão do Estado de São Paulo, onde a jovem autora era violentamente atacada, teve como resultado direto aquilo que mais tarde Mário de Andrade denominou de "arregimentação, a consciência de rebeldia, de espírito novo". Realmente, o súbito ataque conseguiu a união em torno de Anita, de Oswald e Mário de Andrade.

Pouco depois o pequeno grupo que já contava com Di Cavalcanti e Guilherme de Almeida, obtém a adesão poderosa de Menotti, do Correio Paulistano, onde fazia crônicas de elogio ao Modernismo. Com isso afirmou Manuel Bandeira, que "o impulso inicial do movimento modernista veio das artes plásti- 
cas" (11).

A 28 de julho de 1918, após retornar da Europa, assume a presidência do país Epitácio Pessoa. Sua vitória nas eleições presidenciais fora fruto de uma conturbada campanha eleitoral.

Os anos de 1920 e 1921 foram marcados por publicações como as de Oliveira Viana, que reformulando a história social do Brasil, procurava explicar e compreender o presente pelo passado em "Instituições Políticas Brasileira" e "Populações Meridionais no Brasil". Outros tentavam "configurar o futuro por meio de um programa de reforma intelectual e moral, inspirados no mesmo conhecimento da nossa real realidade» (12). Um deles era Cincinato Braga, que reuniu em 1921 uma série de artigos sob o título de "Problemas Brasileiros".

"A consciência de uma realidade até então desapercebida teria forçosamente de determinar modificações nos processos artísticos, que são, justamente, as formas estéticas de sua representação..." (13). O Modernismo já "Estava no ar", em 1921, embora sob a forma ainda obscura de um anseio de modernização.

Mário de Andrade em seu artigo "Debussy e o Impressionismo", para a Revista do Brasil, apresenta Di Cavalcanti.

\footnotetext{
"como um destes jovens que, cheios de estranho vigor e galharda independên cia , vêm revolucionando as idéias no campo da literatura e da arte, em São Paulox.
}

E, segundo Mário da Silva Brito em "A Literatura no Brasil», «... os modernistas de São Paulo estavam preparados para romperem as amarras culturais", fazendo deste movimento algo "esteticamente europeu, mas doutrinariamente nacionalista" (14).

Em 13 de fevereiro de 1922, Semana da Arte Moderna, São Paulo. Na Sessão Inaugural, a conferência proferida por Graça Aranha "A emoção estética na Arte Moderna", apresenta a Semana de Arte "como uma livre manifestação do gênio criador, contra a qual não poderiam prevalecer nem o «nefando bom goston nem o «infecundo bom senso" (15). Graça Aranha empregou pela primeira vez a palavra Modernismo, e apresentou Guilherme de Almeida e Ronald de Carvalho, "os dois poetas da noitada", e referiu-se aos artistas a que ficava confiada a "remodelação estética do Brasil», Vila-Lobos, na música; Brecheret, na escultura; Di Cavalcanti, Anita Malfatti, Vicente do Rego Monteiro e Zina Aita na pintura, "além da jovem e ousada poesia que devia arredar os perigos do arcadismo, do academismo e do provincianismo". O regionalismo, para Graça Aranha, era utilizável «mas não o fim de uma literatura nacional aspirando ao universal» (16).

Estavam assim lançadas concretamente as bases do Movimento Modernista Brasileiro. 
O desenvolvimento das relações capitalistas, no Brasil, ganhou celeridade com a Primeira Guerra Mundial e, particularmente, depois dela quando iniciase uma nova fase marcada não só pelas idéias de nacionalismo como também pelas tentativas de reforma no plano cultural, político e social.

\title{
Com o
}

\begin{abstract}
«mercado interno à sua mercê, livre da concorrência esmagadora do produtor externo, a indústria nacional operou grande avanço; a acumulaçăo interna cresceu, não apenas devido ao surto industrial, mas também porque, reduzidos os investimentos estrangeiros aqui, reduzidas foram as retiradas de seus lucros. Claro que, cessada a Guerra Mundial, tudo tenderia a voltar ao quadro antigo; mas ai os capitais nacionais haviam crescido, as relaçoes capitalistas se haviam desenvolvido muito e a luta travaria-se já em outro nivel» (17).
\end{abstract}

Além da industrialização, da acumulação interna, da urbanização e do crescimento demográfico, surgem novas instituições e há uma nova divisão de tarefas. "Há um relacionamento de tipo secundário, impessoal, indiferente, que não liga entre si individuos e sim categorias de individuos, representantes de uma categoria ocupacional ou de uma categoria econômica” (18).

Alteram-se as relações na esfera do poder. O sistema oligárquico é portador de contradições. Há uuma paradoxal coexistência de uma ideologia liberal com padrões de comportamento oligárquico e tradicional. É justamente essa contradição que vai ser alvo, durante os anos vinte, das críticas ao sistema oligárquico, venham elas dos "autênticos liberais" (com os membros do Partido Liberal, do PD), dos precursores do autoritarismo, ou dos chamados "tenentes». Essa coexistência não é somentè uma característica fundamental do liberalismo, ao surgir na Europa (defendendo a liberdade econômica da burguesia contra os privilégios da classe agrária, ou a liberdade política contra o absolutismo), nunca existiu na América Latina» (19).

Nessa década e na seguinte os teóricos brasileiros do nacionalișmo e do autoritarismo souberam captar essas contradições ao montar suas críticas ao sistema oligárquico. Entre eles, cita-se: Azevedo Amaral, oliveira Viana, Alberto Torres e Francisco Campos, este último autor da «constituição autoritária", que inaugurou o Estado Novo.

Em meio a essas contradições, a cidade de São Paulo começa a metamorfosear-se em grande cidade. São Paulo, a moderna cidade abriga 1922.

A proximidade das comemorações do Centenário da Independência do Brasil impulsionara a construção de novas obras e seria, no dizer de Aracy Amaral, essa "construção de cidades" que tanto empolgaria a Mário de Andrade como a Oswald de Andrade, tornando-os os poetas da cidade. "Mário, em Paulicéia Desvairada, uma ode ao progresso da cidade que se metropolizava, e em Oswald de "Os Condenados», um amor estranho à cidade que palmilha quarteirão por quarteirão, captando toda a atmosfera de um centro em ebulição em seus diversos bairros" (20): 
São Paulo com seus jardins, edifícios monumentais, praças ajardinadas, Palácio do Governo, Museu do Ipiranga, Teatro Municipal, Estação da Luz, Avenida Paulista recém aberta, bem como sua vizinha Avenida Angélica, constituiam atrações para os visitantes.

Saindo de Higienópolis, bairro da "aristocracia" do café em seus anos de fartura, passando pelas construções que embelezam a capital do mais rico estado do Brasil, olha-se de relance "uma classe operária mal paga e mal nutrida. O operário paulista, em 1920, trabalhava dez horas por dia, por 4 mil réis, o equivalente de 60 centavos de dólar, menos ainda do que ganhavam os colonos das fazendas de café. Começava-se a falar em questão social, fundavam-se sindicatos, explodiam greves - uma delas, em 1917 (21), paralisou toda a nascente indústria - prendiam-se agitadores, socialistas e anarquistas" (22).

Contudo, os jovens intelectuais preferiam freqüentar o encantado bairro de Higienópolis. Pode-se dizer que dali saiu a Semana diretamente para o Teatro Municipal.

Rubens Borba de Moraes explicava há alguns anos: «Politica, problemas econômicos e sociais, luta de classes, sabíamos o que era por vagas leituras, mas não nos interessavam. Vivíamos à margem desses problemas cabeludos". Para concluir, "o que caracterizou a Semana foram a liberdade e a alegria de viver" (23), ou a alienação?

A partir das palavras de Rubens Borba de Moraes, a Semana caracteriza, nessa medida, um dos "dois Brasis", o do fausto, aquele que congrega os barões do café, os exportadores e os industriais, os que serão os mecenas.

São Paulo possuía o capital, a disponibilidade e a irreverência revolucionária de um Freitas Valle ou de um Paulo Prado; e a "semana" foi patrocinada por uma dúzia de senhores do café, "os doze apóstolos", como os chamava Oswald de Andrade - que a chamado de Paulo Prado, haviam conseguido subvenções das autoridades e tinham entrado até com algum dinheiro. No final, houve um prejuizo de seiscentos e poucos mil réis por cabeça (não esquecer que um operário recebia por "cabeça", 4 mil réis por dia).

$\mathrm{Na}$ Vila Kyrial, na casa do senador gaúcho Freitas Valle, "centralizava-se, de certa forma, o mundo intelectual e artístico de São Paulo, bem como era ponto de reunião de artistas e jornalistas de passagem pela (...) capital. O senador gaúcho recebia às quartas-feiras, casa aberta para poetas, amigos e pintores. Discutia-se, ouvia-se música, havia regularmente conferências sobre literatura, história, arte" (24).

Oswald de Andrade, referindo-se certa vez às «reuniões avinhadas da Vila Kyrial", disse ser uma "mistura que definia bem a época": "homens do futuro, homens do passado, políticos, intelectuais e pseudo-intelectuais, estrangeiros, nativos, artistas, bolsistas da Europa, toda uma fauna sem bússola em torno da gota anfitriã do senador poeta” (25).

Os acontecimentos mundanos nos primeiros tempos do movimento moder- 
nista (recepções, espetáculos, vernissages, concertos) e que lhes davam ocasião de divulgar suas doutrinas e suas obras, permitem compreender o mecenato que então exercia a fração intelectualizada e "ueuropeizada” dos grupos dirigentes paulistas".

Participavam destas reuniões: Coelho Neto, João do Rio, Menotti del Picchia, René Thiollier, Paulo Prado, Oswald de Andrade, Mário de Andrade, Osório César e Souza Lima, entre outros.

"As viagens à Europa, o aprendizado dos modelos estéticos e éticos de vanguar$\mathrm{da}$, as formas requintadas de consumo, tudo isso impregna as obras dos escritores modernistas que dependiam das prodigalidades dos mecenas que mantinham salôes na capital do estado. Embora alguns dentre os escritores modernistas tenham se tornado mais tarde semi-profissionais da produçăo líteráriale artistica, as obras da primeira leva se destinavam a um circulo bastante reduzido de iniciados, pertencentes a familias abastadas da oligarquia local, e que detinham as chaves para decifrar tais obras" (26).

Sérgio Miceli dedica algumas páginas ao que ele chama de «estado maior intelectual do comando perrepista". Encabeça esse "estado maior" Paulo Prado, comerciante de café, principal sócio da firma Prado Chaves, historiador e critico literário, monarquista (sic), conhecedor de Marx e dos escritores politicos da época, futuro fundador do Partido Democrático, oposição.

A Semana é noticiada através da Gazeta de São Paulo, da Folha da Noite, do Correio Paulistano e de O Estado de São Paulo. O Correio Paulistano - órgão do Partido Republicano Paulista, partido tradicionalmente oligárquico - dá ampla cobertura. Nele assinam, entre outros, Menotti, Cassiano Ricardo, Candido Motta Filho, todos ligados ao movimento modernista. O Estado de São Paulo que se apresenta como um órgão independente que pelos laços doutrinários se aproxima da oposição em 1926, não dá a mesma cobertura à "Semana» e não reúne em seus quadros os chamados modernistas. É portanto o jornal que representa a situação que cobre a revolucionária Semana de Arte, ambos sob o patrocínio de alguns senhores do café: paulistas possuidores do capital, da disponibilidade e irreverência revolucionária.

«O acesso dos modernistas às frentes de vanguardas europeia por força de sua proximidade social junto aos circulos intelectualizados da oligarquia foi, paradoxalmente, a condição que lhes permitiu assumir o papel de inovadores culturais e estéticos no campo literário local, tomando a dianteira no processo de asubstituiçăo de importaçoes" de bens culturais e desbancando seus principais concorrentes" (27).

Ê comum associar a Semana de Arte Moderna ao processo revolucionário, colocando-se como uma das causas da queda do sistema oligárquico que marcou a Revolução de 1930 . No entanto, a divulgação pela imprensa e a opinião escrita dos próprios artístas, demonstrou que, por exemplo, o alugueiel do Teatro Municipal de São Paulo, bem como os tantos mil réis gastos durante a Semana de Arte | foram patrocinados por alguns representantes da oligarquia paulista.

Como então associar os modernistas de 1922 aos movimentos políticos que contestavam esta mesma oligarquia, então no poder? 
1922 foi o marco da deflagração de uma crise que culminou com o término da Primeira República, isto é certo.

Se de um lado havia o descontentamento dos tenentes, das oligarquias periféricas, dos setores médios da sociedade, do operariado emergente, do outro houve a tentativa da oligarquia paulista de modernização. Tentativa esta, engendrada por essas pressões.

E a Semana da Arte Moderna insere-se nesta última.

Se os tenentes representantes de um grupo descontente buscavam no quadro nacional, alterações que implicariam numa revolução, o grupo dominante paulista, numa atitude conservadora pretende reformar um edifício sem alterar-lhe as estruturas. As artes estavam impregnadas de modernismo e poderia partir delas a pretendida reforma. Porém, os homens do P.R.P. não perceberam que o modernismo estava impregnado de nacionalismo, e, sobretudo não perceberam a intenção do nacionalismo brasileiro.

Haverá em 1926 uma cisão no seio do P.R.P., quando homens como Paulo Prado, que já havia desejado mudanças através das artes, descobrem sua ineficácia e partem em busca de novos instrumentos para manterem sua hegemonia.

Graças a isso, o Modernismo brasileiro ganhou sua liberdade, depois de ter explodido sob o patrocínio de uma oligarquia. Resultou da discutida intenção deste patrocínio a integração do nacionalismo brasileiro à realidade. A inconseqüência dos "mecenas modernistas" teve como fruto somente a revolução nas artes.

e,

"Se a funçăo da consciência é explodir um mundo, podemos dizer que com a Semana da Arte Moderna, em 1922, realizamos uma primeira tentativa de real independência cultural face ao passado europeu e aos modelos estrangeiros. Com exagero - este sim, bastante nosso - efetuamos a constatação do óbvio: à nossa volta năo havia fogo, neve ou castelos medievais - mas bananeiras, coqueiros, casas de caboclos e gente de nariz batatudo e lábios grossos. O parnaso|super-refinado, os traços suaves das madonas, o bom gosto oficial vieram abaixo; nossos artistas retiraram de seus ombros a carga de um passado alheio e que lhes pesava. Tornava-se possivel criar. O resultado foi uma revolução. De Mário e Oswald e Joăo Cabral de Melo Neto, súbito percorremos os caminhos de uma emancipação artistica. Os imensos pés das figuras de Portinari denunciam: encontrou-se um chão sobre o qual pisar». (28)

Roberto Gomes: "Critica da Razăo Tupiniquim". 


\section{NOTAS}

(1) BANDEIRA, Manuel. Crônicas das Províncias do Brasil. Rio de Janeiro, Civilizaçăo Brasileira, 1937, p. 93. In: AMARAL, Aracy. Artes Plásticas na Semana de 22, São Paulo, Ed. Perspectiva, 1979, p. 50.

(2) MARTINS, Wilson. História da Inteligência Brasileira. São Paulo, Ed. Cultrix, 1978, p. 35.

(3) Idem, p. 39.

(4) Idem, p. 49.

(5) Idem, p. 39.

(6) Idem, p. 40.

(7) Idem, p. 40.

(8) Idem, p. 41.

(9). CASTRO, Silvio. Teoria e Politica do Modernismo Brasileiro. Petrópolis, Ed. Vozes, 1979 , p. 100.

(10) MARTINS, Wilson. op. cit., p. 97.

(11) AMARAL, Aracy. Op. cit., p. 18.

(12) MARTINS, Wilson, op. cit., p. 197.

(13) Idem, p. 232.

(14) Idem, p. 226.

(15) AMARAL, Aracy, op. cit., p. 96.

(16) Idem p. 239.

(17) WERNECK SODRÉ, Nelson. Sintese da História da Cultura Brasileira. $4^{a}$ ed. Rio de Janeiro. Ed. Civilização Brasileira 1976, p. 55.

(18) PACHECO BORGES, V. Getúlio Vargas e a Oligarquia Paulista. Sāo Paulo, Ed. Brasiliense, 1979, p. 23 e 24.

(19) Idem, p. 23.

(20) AMARAL, Aracy, op. cit., p. 43.

(21) A greve de 1917 eclodiu em diverssas regiões do Brasil. No Rio Grande do Sul, assumiu grandes proporções ao atingir todo o Estado. O governo Estadual, Borges de Medeiros, viu-se obrigado a intervir para solucionar a questão.

(22) Revista Realidade: "50 anos de Arte Moderna", Ed. Abril (texto de Mino CArta), p.22.

(23) Idem, p. 22.

(24) AMARAL, Aracy. op. cit., p. 89.

(25) Idem, p. 92.

(26) MICELI, Sérgio. Intelectuais e Classe Dirigente no Brasil». São Paulo, Difel, 1979, p. 13.

(27) Idem, p. 15.

(28) GOMES, Roberto. Critica da Razão Tupiniquim. Porto Alegre, Movimento, UFRGS, 1979 , p. 87 . 